\title{
Palladium-Catalyzed intramolecular Cyclization of '2-bromo-1,5- di-ene-7-yne'System: A Versatile Route to the Poly-ene Substituted Cyclohexenols
}

\author{
Sunanda Paul, Raju Singha and Jayanta K. Ray * \\ Department of Chemistry, Indian Institute of Technology, Kharagpur 721 302, India \\ Corresponding author: Tel.: +91 3222283326; fax: +91 3222282252 . \\ E-mail address: jkray@ chem.iitkgp.ac.in
}

\begin{abstract}
A general and efficient methodology has been developed for the synthesis of substituted cyclohexenol system with conjugated bis-exocyclic diene via Pd-catalyzed intramolecular 6-exo-dig cyclization of 'ene-yne' moiety. This method is straight forward and high yielding.
\end{abstract}

Poly-ene-substituted cyclohexenol moiety has been found as a useful scaffold for the construction of numerous naturally occurring and biologically active molecules (Figure 1).

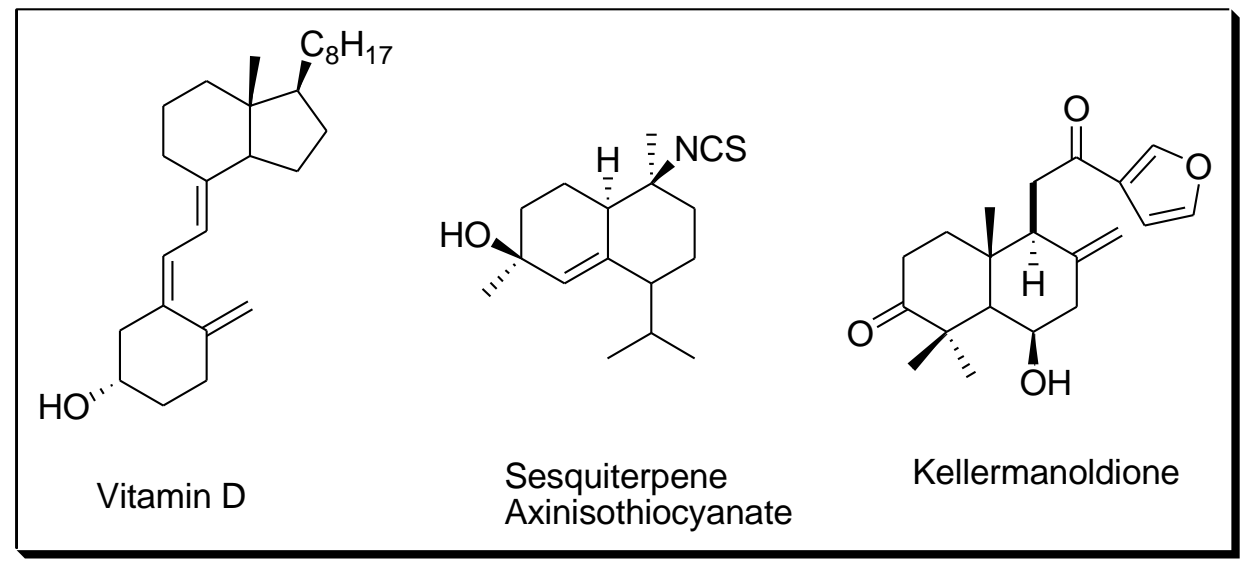

Figure 1: Natural products containing polyene substituted cyclohexenols

Vitamin D attracts much attention due to the unique specificity and selectivity of their formation in vivo, as well as their bioactivity and the therapeutic properties ${ }^{1}$. Bicyclic sesquiterpenes containing isocyano, isothiocyanate are secondary metabolites isolated from sponges of the genus Axinyssa. Biological activities such as antihelmintic, antimicrobial, and cytotoxic properties have been ascribed to these nitrogen containing sesquiterpenes ${ }^{2}$. Kellermanoldione, 
containing cyclohexanol moiety with exocyclic double bond, is a labdane diterpene isolated from Brickellia kellermanii Grenm, a shrub which is reported to have potent antidiarrhetic properties and is used in Mexican folk medicine ${ }^{3}$.

Rhodium- and Palladium-catalysed formation of six-membered ring with conjugated mono- and bis-exocyclic diene was reported by Grigg and coworkers (Scheme 1) ${ }^{4}$.

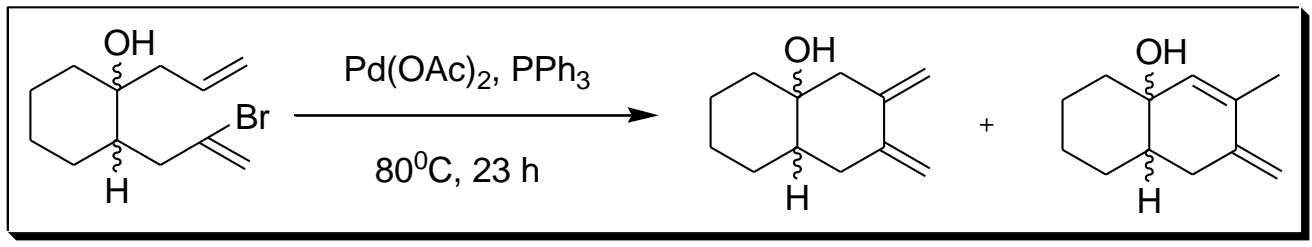

Scheme 1: Synthesis of conjugated 6-membered bis-exocyclic dienes

Mascareñas and coworkers synthesized bis-exocyclic conjugated diene system of vitamin D r synthons by palladium-catalyzed intramolecular cyclization of the (Z)-iodoalkene resulting from the stereoselective hydrometallation-iodinolysis of propargylic alcohol (Scheme 2) ${ }^{5}$.

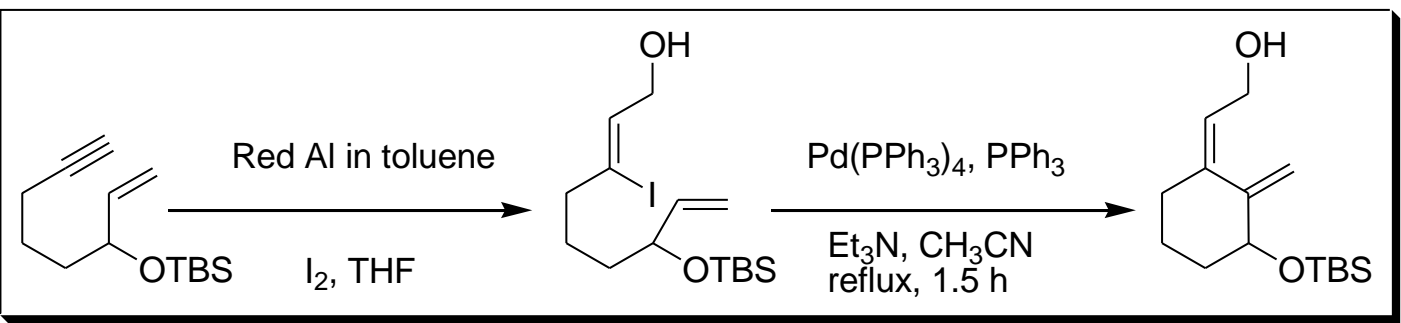

Scheme 2: Synthesis of bis-exocyclic conjugated diene system of vitamin D ring A synthons

On the basis of our previous studies on the Pd catalyzed cyclization of substrates derived from $\beta$ bromovinyl aldehydes ${ }^{6-31}$, here we planned to develop a new route to cyclohexenol skeleton with conjugated diene by exploiting intramolecular Heck cyclization starting from a novel substrate (Scheme 3). 


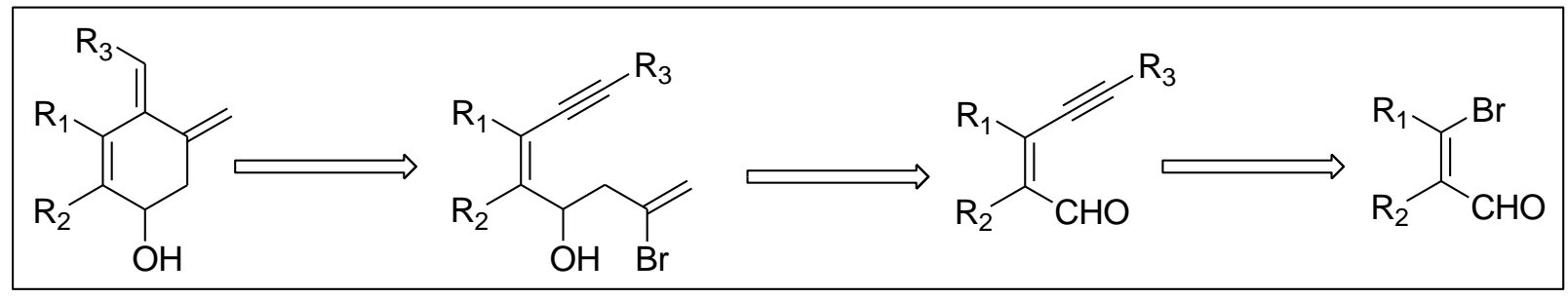

Scheme 3: Disconnection approach from cyclohexenol to bromo-vinyl aldehyde

\section{Results and Discussion:}

The convergent method involved the preparation of the precursors $(\mathbf{3 a}-\mathbf{3 j})$ which were synthesized from $\beta$-bromovinyl aldehydes as per Scheme 4.

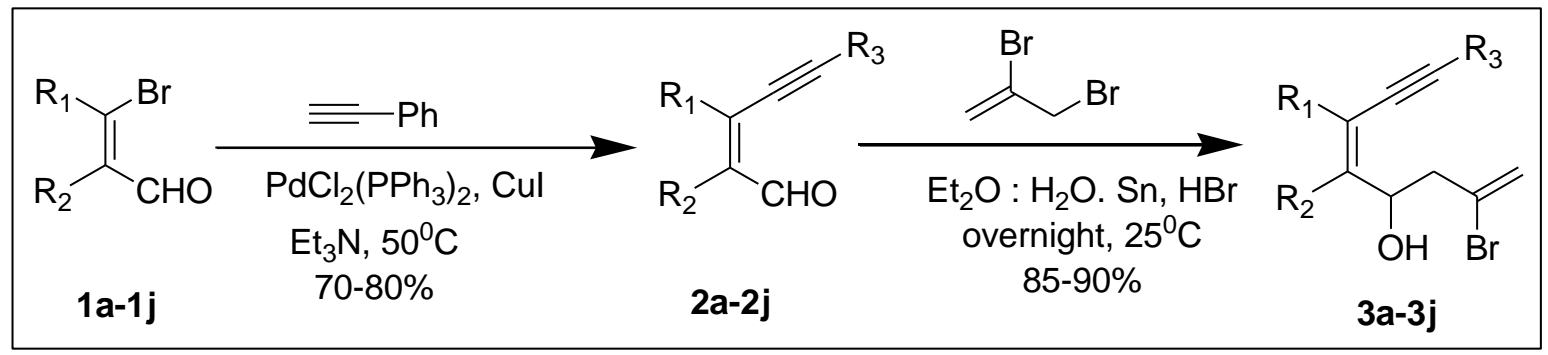

Scheme 4: Preparation of 2-bromo-8-phenyl-octa-1,5-diene-7-yn-4-ol

The precursors were synthesized in good to excellent yield by Sonogashira coupling 5 of $\beta$ bromovinylaldehydes with ethynyl benzene using $\mathrm{PdCl} 2(\mathrm{PPh} 3) 2(2 \mathrm{~mol} \%)$ and $\mathrm{CuI}(1 \mathrm{~mol} \%)$ as catalyst in Et $3 \mathrm{~N}$ as solvent at $50{ }^{\circ} \mathrm{C}$ for $6-7 \mathrm{hr}$. followed by $\mathrm{Sn}(1.5 \mathrm{mmol})$ mediated allylation6 with 2,3-dibromo propene ( $3 \mathrm{mmol})$ in $\mathrm{Et}_{2} \mathrm{O}: \mathrm{H}_{2} \mathrm{O}(3: 1)$ medium to afford the precursor 2-Bromo8-phenyl-octa-1,5-diene-7-yn-4-ol (3a-3j) in good (85-90\%) yield (Scheme 1.42). The Heck precursors on treatment with $\mathrm{Pd}(\mathrm{OAc}) 2(5 \mathrm{~mol} \%), \mathrm{PPh} 3(0.5 \mathrm{mmol})$ and HCOONa (1.0 mmol) in DMF at $80{ }^{\circ} \mathrm{C}$ yielded 4-benzylidene- 5-methylene-cyclohex-2-enol (4a-4j) as the only isolable product. 


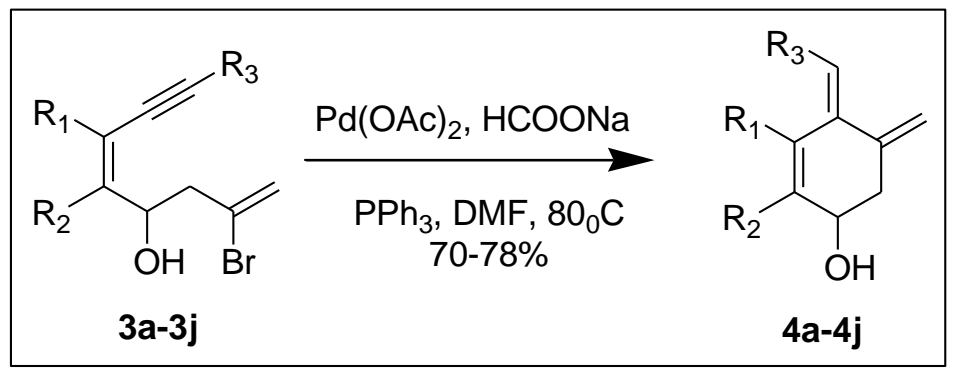

Scheme 5: Heck cyclization of 2-bromo-8-phenyl-octa-1,5-diene-7-yn-4-ol

Stereoselectively only one isomer was isolated. However stereochemistry of the product was rigorously established and also based on the mechanism of palladium-catalyzed-exo-dig cyclization $^{32}$ followed by trapping of cyclopalladium intermediate with the hydride, the stereochemistry of product is expected to be the more stable $E$-isomer as shown in Scheme $6^{33,34}$. Several applications and usefulness have been cited in recent publications ranging from natural product derivation to biomedical applications ${ }^{15,17,35-53}$.

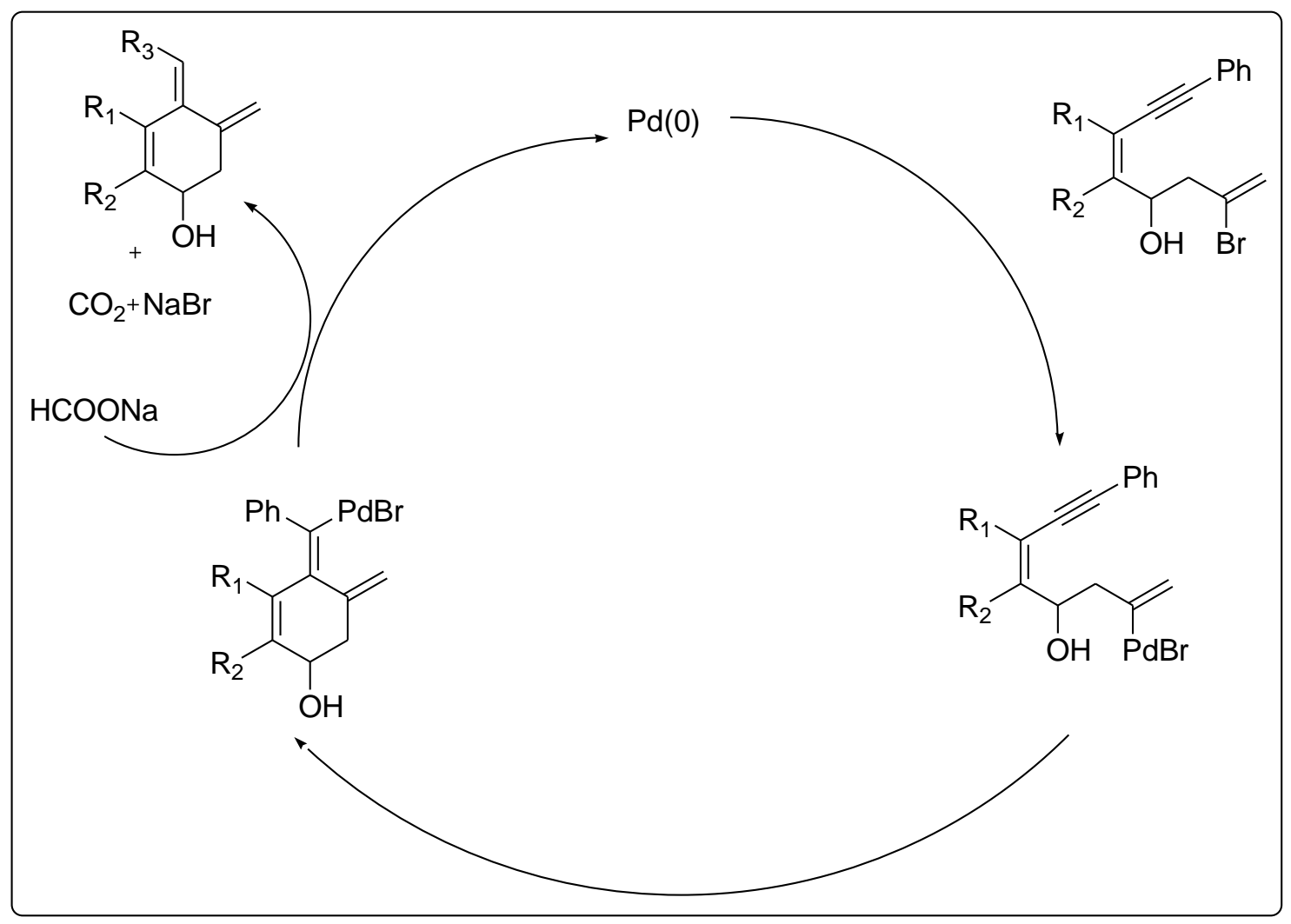

Scheme 6: Mechanism of Pd-catalyzed exo-dig cyclization 
With this strategy a number of 6-membered bis-exocyclic dienes were synthesized (Table 1)

Entry




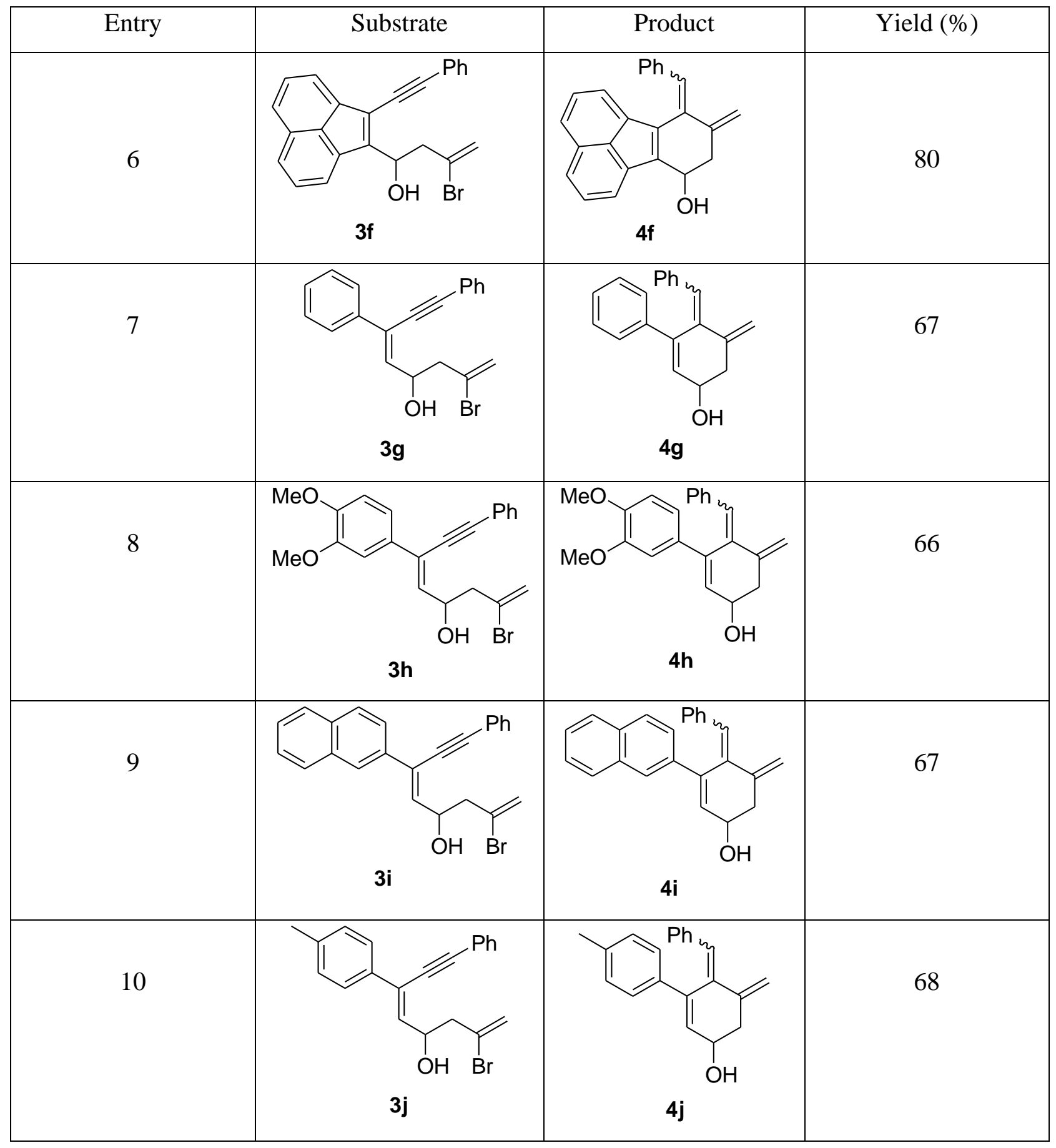




\section{Conclusion:}

In short, we have outlined an important synthetic protocol for the construction of 6- membered ring via Pd-catalyzed intramolecular 6-exo-dig cyclization of 'ene-yne' moiety. The developed method is simple, straight forward and high yielding. The formed cyclohexenol system with conjugated bis-exocyclic diene can be taken as an effective Diels-Alder precursor.

Acknowledgement : The authors wish to thank DST and CSIR (New Delhi) for financial support.

\section{References:}

1. Dmitrenko, O.; Frederick, J.; Reischl, W., Ab initio study of conformational stability in previtamin D, vitamin D and related model compounds. Journal of Molecular Structure: THEOCHEM 2000, 530 (1-2), 85-96.

2. Zubia, E.; Ortega, M. J.; Hernández-Guerrero, C. J.; Carballo, J. L., Isothiocyanate sesquiterpenes from a sponge of the genus Axinyssa. Journal of natural products 2008, 71 (4), 608-614.

3. Jung, M. E.; Cordova, J.; Murakami, M., Total Synthesis of $( \pm)$-Kellermanoldione: Stepwise Cycloaddition of a Functionalized Diene and Allenoate. Organic letters 2009, 11 (17), 3882-3885.

4. Grigg, R.; Sridharan, V.; Stevenson, P.; Worakun, T., Palladium (II) catalysed construction of tetrasubstituted carbon centres, and spiro and bridged-ring compounds from enamides of 2-lodobenzoic acids. Journal of the Chemical Society, Chemical Communications 1986, (23), 1697-1699.

5. Mascareñas, J. L.; García, A. M.; Castedo, L.; Mouriño, A., A short, efficient route to 1hydroxylated vitamin D ring A fragments. Tetrahedron letters 1992, 33 (30), 4365-4368.

6. Ghosh, M.; Ray, J. K., Ten years advancement in the synthetic applications of 2-bromocyclohexenecarbaldehydes and 2-bromobenzaldehydes and derived substrates under palladiumcatalyzed cross-coupling conditions. Tetrahedron 2017, 73 (27-28), 3731-3799.

7. Roy, B. C.; Gupta, M. D.; Bhoumik, L.; Ray, J. K., Spectroscopic investigation of water-soluble polyaniline copolymers. Synthetic Metals 2002, 130 (1), 27-33.

8. Brahma, S.; Ray, J. K., Halovinyl aldehydes: useful tools in organic synthesis. Tetrahedron 2008, 64 (13), 2883-2896.

9. Ray, J.; Bhowmik, L., Sol Gel Technique to Prepare Composite Material of Glass-DyePolymers. 2021.

10. Ray, J.; Bhowmik, L., Preparation and Evaluation of Novel Bamboo-Polymer Composites. 2021.

11. Sarkar, P.; Ahmed, A.; Ray, J. K., Suzuki cross coupling followed by cross dehydrogenative coupling: An efficient one pot synthesis of Phenanthrenequinones and analogues. Tetrahedron Letters 2020, 61 (13), 151701. 
12. Ray, J. K.; Singha, R.; Ray, D.; Ray, P.; Rao, D. Y.; Anoop, A., Palladium-catalyzed expedient Heck annulations in 1-bromo-1,5-dien-3-ols: Exceptional formation of fused bicycles. Tetrahedron Letters 2019, 60 (13), 931-935.

13. Ray, J. K.; Paul, S.; Ray, P.; Singha, R.; Rao, D. Y.; Nandi, S.; Anoop, A., Pdcatalyzed intramolecular sequential Heck cyclization and oxidation reactions: a facile pathway for the synthesis of substituted cycloheptenone evaluated using computational studies. New Journal of Chemistry 2017, 41 (1), 278-284.

14. Chaudhuri, S.; Maity, S.; Roy, M.; Ray, P.; Ray, J. K., A Vinyl Radical Cyclization Route to Hydroxycyclohexene Fused Carbocycles. Asian Journal of Chemistry 2016, 28 (1).

15. Brahma, S.; Ray, P.; Singha, R.; Ray, J. K., Visible Colourimetric and Ratiometric Fluorescent Chemosensors for Cu (II) and Ni (II) Ions. Asian Journal of Chemistry 2016, 28 (5), 1035.

16. Nandi, S.; Singha, R.; Ray, J. K., Palladium catalyzed intramolecular cascade type cyclizations: Interesting Approach towards naphthoquinone derivatives having an O-containing heterocyclic skeleton. Tetrahedron 2015, 71 (4), 669-675.

17. Ray, D.; Nasima, Y.; Sajal, M. K.; Ray, P.; Urinda, S.; Anoop, A.; Ray, J. K., Palladium-Catalyzed Intramolecular Oxidative Heck Cyclization and Its Application toward a Synthesis of $( \pm)-\beta$-Cuparenone Derivatives Supported by Computational Studies. Synthesis 2013, 45 (09), 1261-1269.

18. Nandi, S.; Singha, R.; Samanta, S.; Ray, J. K., Synthesis of pentalongin and C (1)-and C (3)-substituted pentalongin using intramolecular Heck reaction. Tetrahedron Letters 2012, 53 (21), 2659-2661.

19. Paul, S.; Samanta, S.; Ray, J. K., Palladium-catalyzed one-pot Suzuki coupling followed by arylpalladium addition to aldehyde: A convenient route to fluoren-9-one derivatives. Tetrahedron Letters 2010, 51 (42), 5604-5608.

20. Samanta, S.; Mohapatra, H.; Jana, R.; Ray, J. K., Pd (0) catalyzed intramolecular Heck reaction: a versatile route for the synthesis of 2-aryl substituted 5-, 6-, and 7-membered Ocontaining heterocycles. Tetrahedron Letters 2008, 49 (50), 7153-7156.

21. Jana, R.; Samanta, S.; Ray, J. K., Substrate dependent intramolecular palladiumcatalysed cyclisation and subsequent $\beta$-H elimination or $\mathrm{C}-\mathrm{H}$ activation: a general method for the synthesis of fused pyran rings. Tetrahedron Letters 2008, 49 (5), 851-854.

22. Jana, R.; Chatterjee, I.; Samanta, S.; Ray, J. K., Novel and rapid palladium-assisted 6pi electrocyclic reaction affording 9,10-dihydrophenanthrene and its analogues. Org Lett 2008, 10 (21), 4795-7.

23. Ray, D.; Ray, J. K., Novel Synthetic Approach Toward ( \pm )- $\beta$-Cuparenone via PalladiumCatalyzed Tandem Heck Cyclization of 1-Bromo-5-methyl-1-aryl-hexa-1, 5-dien-3-ol Derivatives. Organic letters 2007, 9 (2), 191-194.

24. Mal, S. K.; Ray, D.; Ray, J. K., Palladium-catalyzed tandem oxidative cyclization of 1bromohexa-1,5-dien-3-ols: easy access to cyclopentenones. Tetrahedron Letters 2004, 45 (2), 277-279.

25. Ray, J. K., Stereoselective Synthesis of Bioactive Compounds (Track) Use of "halo vinyl aldehydes" in organic synthesis and chemo selective functional group transformations in gamma lactam derivatives.

26. Ray, P.; Gidley, D.; Badding, J. V.; Lueking, A. D., UV and chemical modifications of polymer of Intrinsic Microporosity 1 to develop vibrational spectroscopic probes of surface chemistry and porosity. Microporous and Mesoporous Materials 2019, 277, 29-35. 
27. Ray, P.; Xu, E.; Crespi, V. H.; Badding, J. V.; Lueking, A. D., In situ vibrational spectroscopy of adsorbed nitrogen in porous carbon materials. Physical Chemistry Chemical Physics 2018, 20 (22), 15411-15418.

28. Ray, P.; Gray, J. L.; Badding, J. V.; Lueking, A. D., High-Pressure Reactivity of Triptycene Probed by Raman Spectroscopy. The Journal of Physical Chemistry B 2016, 120 (42), 11035-11042.

29. Ray, P., Interactions of nitrogen and hydrogen with various $1 \mathrm{D}$ and $3 \mathrm{D}$ carbon materials probed via in-situ vibrational spectroscopy. Ph. D. Thesis 2016.

30. Wang, C.-Y.; Ray, P.; Gong, Q.; Zhao, Y.; Li, J.; Lueking, A. D., Influence of gas packing and orientation on FTIR activity for $\mathrm{CO}$ chemisorption to the $\mathrm{Cu}$ paddlewheel. Physical Chemistry Chemical Physics 2015, 17 (40), 26766-26776.

31. Brahma, S.; Ray, P.; Ray, J. K., Synthesis of azirines containing aldehyde functionality and their utilization as synthetic tools for five membered oxazoles and isoxazoles (vol 45, pg 311, 2008). JOURNAL OF HETEROCYCLIC CHEMISTRY 2021, 58 (6), 1388-1388.

32. Roesch, K. R.; Larock, R. C., Synthesis of isoquinolines and pyridines by the palladium/copper-catalyzed coupling and cyclization of terminal acetylenes and unsaturated imines: the total synthesis of decumbenine B. The Journal of organic chemistry 2002, 67 (1), 8694.

33. Mandai, T.; Nokami, J.; Yano, T.; Yoshinaga, Y.; Otera, J., Facile one-pot synthesis of bromo homoallyl alcohols and 1, 3-keto acetates via allyltin intermediates. The Journal of Organic Chemistry 1984, 49 (1), 172-174.

34. Oh, C. H.; Park, S. J., Palladium-catalyzed cycloreductions of haloene-ynes in the presence of triethylsilane. Tetrahedron letters 2003, 44 (19), 3785-3787.

35. Das, A.; Haque, I.; Ray, P.; Ghosh, A.; Dutta, D.; Quadir, M.; De, A.; Gunewardena, S.; Chatterjee, I.; Banerjee, S.; Weir, S.; Banerjee, S. K., CCN5 activation by free or encapsulated EGCG is required to render triple-negative breast cancer cell viability and tumor progression. Pharmacol Res Perspect 2021, 9 (2), e00753.

36. Ray, P.; Haideri, N.; Haque, I.; Mohammed, O.; Chakraborty, S.; Banerjee, S.; Quadir, M.; Brinker, A. E.; Banerjee, S. K., The Impact of Nanoparticles on the Immune System: A Gray Zone of Nanomedicine. Journal of Immunological Sciences 2021, 5 (1).

37. Ray, P.; Dutta, D.; Haque, I.; Nair, G.; Mohammed, J.; Parmer, M.; Kale, N.; Orr, M.; Jain, P.; Banerjee, S.; Reindl, K. M.; Mallik, S.; Kambhampati, S.; Banerjee, S. K.; Quadir, M., pH-Sensitive Nanodrug Carriers for Codelivery of ERK Inhibitor and Gemcitabine Enhance the Inhibition of Tumor Growth in Pancreatic Cancer. Molecular Pharmaceutics 2021, 18 (1), 87-100.

38. Ray, P.; Kale, N.; Quadir, M., New side chain design for pH-responsive block copolymers for drug delivery. Colloids and Surfaces B: Biointerfaces 2021, 200, 111563.

39. Babak, K.; Torabi, M.; Foad, K.; Priyanka, R., Novel $\beta$-Cyclodextrin Functionalized Core-Shell Fe3O4 Magnetic Nanoparticles for the Removal of Toxic Metals from Water. 2021.

40. Abdullah, C. S.; Ray, P.; Alam, S.; Kale, N.; Aishwarya, R.; Morshed, M.; Dutta, D.; Hudziak, C.; Banerjee, S. K.; Mallik, S.; Banerjee, S.; Bhuiyan, M. S.; Quadir, M., Chemical Architecture of Block Copolymers Differentially Abrogate Cardiotoxicity and Maintain the Anticancer Efficacy of Doxorubicin. Molecular Pharmaceutics 2020, 17 (12), 4676-4690.

41. Clément, M.; Abdellah, I.; Ray, P.; Martini, C.; Coppel, Y.; Remita, H.; Lampre, I.; Huc, V., Synthesis and NMR study of trimethylphosphine gold(i)-appended calix[8]arenes as precursors of gold nanoparticles. Inorganic Chemistry Frontiers 2020. 
42. Confeld, M. I.; Mamnoon, B.; Feng, L.; Jensen-Smith, H.; Ray, P.; Froberg, J.; Kim, J.; Hollingsworth, M. A.; Quadir, M.; Choi, Y.; Mallik, S., Targeting the tumor core: hypoxiaresponsive nanoparticles for delivery of chemotherapy to pancreatic tumors. Molecular Pharmaceutics 2020.

43. Sarker, N. C.; Ray, P.; Pfau, C.; Kalavacharla, V.; Hossain, K.; Quadir, M., Development of Functional Nanomaterials from Wheat Bran Derived Arabinoxylan for Nucleic Acid Delivery. Journal of Agricultural and Food Chemistry 2020, 68 (15), 4367-4373.

44. Ray, P.; Confeld, M.; Borowicz, P.; Wang, T.; Mallik, S.; Quadir, M., PEG-b-poly (carbonate)-derived nanocarrier platform with $\mathrm{pH}$-responsive properties for pancreatic cancer combination therapy. Colloids and Surfaces B: Biointerfaces 2019, 174, 126-135.

45. Ray, P.; Ferraro, M.; Haag, R.; Quadir, M., Dendritic Polyglycerol-Derived NanoArchitectures as Delivery Platforms of Gemcitabine for Pancreatic Cancer. Macromol Biosci 2019, 19 (7), e1900073.

46. Ray, P.; Nair, G.; Ghosh, A.; Banerjee, S.; Golovko, M. Y.; Banerjee, S. K.; Reindl, K. M.; Mallik, S.; Quadir, M., Microenvironment-sensing, nanocarrier-mediated delivery of combination chemotherapy for pancreatic cancer. Journal of Cell Communication and Signaling 2019.

47. Ray, P.; Alhalhooly, L.; Ghosh, A.; Choi, Y.; Banerjee, S.; Mallik, S.; Banerjee, S.; Quadir, M., Size-Transformable, Multifunctional Nanoparticles from Hyperbranched Polymers for Environment-Specific Therapeutic Delivery. ACS Biomaterials Science \& Engineering 2019, 5 (3), 1354-1365.

48. Ghosh, A.; Sarkar, S.; Ghosh, S.; Ray, P.; Quadir, M.; Banerjee, S. K.; Banerjee, S., Abstract 1234: Zoledronic acid-induced suppression of invasive phenotypes of pancreatic cancer cells is mediated through downregulation of CYR61/CCN1. Cancer Research 2019, 79 (13 Supplement), 1234.

49. Ray, P.; Clément, M.; Martini, C.; Abdellah, I.; Beaunier, P.; Rodriguez-Lopez, J.-L.; Huc, V.; Remita, H.; Lampre, I., Stabilisation of small mono- and bimetallic gold-silver nanoparticles using calix[8]arene derivatives. New Journal of Chemistry 2018, 42 (17), 1412814137.

50. André, E.; Boutonnet, B.; Charles, P.; Martini, C.; Aguiar-Hualde, J. M.; Latil, S.; Guérineau, V.; Hammad, K.; Ray, P.; Guillot, R.; Huc, V., A New, Simple and Versatile Strategy for the Synthesis of Short Segments of Zigzag-Type Carbon Nanotubes. Chemistry 2016, 22 (9), 3105-14.

51. Singha, R.; Roy, S.; Nandi, S.; Ray, P.; Ray, J. K., Palladium-catalyzed one-pot Suzuki-Miyaura cross coupling followed by oxidative lactonization: a novel and efficient route for the one-pot synthesis of benzo[c]chromene-6-ones. Tetrahedron Letters 2013, 54 (7), 657660.

52. Ray, P., Curing Cancer with Nanotherapy Continues to be an Elusive Goal. Journal of Immunological Sciences 2021, 5 (2).

53. Ray, P. Calixarenes and Nanoparticles: Synthesis, Properties and Applications. Paris 11, 2013. 